\title{
Política de saúde no terreiro: uma ação que envolve a crença e a ciência
}

\author{
Maria da Conceição da Silva Cordeiro*
}

\section{RESUMO}

Neste artigo, discuto a eficácia simbólico-religiosa e política de um terreiro de candomblé, ao se constituir em centro de atenção à saúde. $\mathrm{O}$ apoio ao Programa Estratégia Saúde da Família tem a finalidade de exercer a vigilância sobre determinadas doenças presentes na população do entorno do terreiro, localizado no bairro das Pedrinhas, no município de Macapá-AP. O complexo de saúde envolve desde a mortalidade materna e infantil, idosos, grupos de risco DST e AIDS até os cuidados do diabetes, da hipertensão e de outras síndromes de significativa incidência nessa faixa da população em sua maioria carente. O artigo constitui-se em uma pesquisa etnográfica, tendo como base minha experiência de trabalho de campo na Amazônia amapaense, especificamente no terreiro do Ylê da Oxum Apará, desde abril de 2013 até os dias atuais. A 'comunicação' entre saúde e sagrado, no ambiente de um terreiro de candomblé, é o primeiro 'estranhamento' que move este estudo: o que permitiu esse arranjo, esse sincretismo entre a prática médica e a prática religiosa? Analiso as interfaces desses dois universos culturais - profissionais de saúde e o status diferenciado que possui o terreiro enquanto agência de saúde na comunidade pesquisada.

Palavras-chaves: saúde; religião; política; Amazônia; cosmologia.

* Doutora em Sociologia pela Universidade Federal do Ceará -UFC e Pesquisadora do Centro de Estudos Políticos, Religião e Sociedade- UNIFAP. E-mail: anancey@bol. com.br. CV: http://lattes.cnpq.br/7892705728411351 


\title{
CURE CROSSROADS: BETWEEN BELIEF AND SCIENCE
}

\begin{abstract}
In this article, I discuss the symbolic-religious and political efficacy of a candomblé terreiro, when it becomes a center of attention to health. Support for the Family Health Strategy Program has the purpose of exercising vigilance over certain diseases present in the population surrounding the terreiro, located in the pebbles district in the municipality of Macapá-Ap. The health complex involves maternal and infant mortality, the elderly, STD and AIDS risk groups, and the care of diabetes, hypertension, and other syndromes with a significant incidence in the majority of the population. This work is based on an ethnographic research, based on my field work experience in Amazonia, specifically in the Ylê terreiro of Oxum Apará, from April 2013 to the present day. The 'communication' between health and sacred, in the environment of a candomble terreiro, is the first 'estrangement' that moves this study: what allowed this arrangement, this syncretism between medical practice and religious practice? I analyze the interfaces of these two cultural universes - health professionals and the differentiated status that the terreiro has as a health agency in the researched community.
\end{abstract}

Keywords: health, culture, politics, Amazon, cosmology

\section{Introdução}

Apesar dos 'segredos guardados', a rotina do terreiro Ylê da Oxum Apará ${ }^{1}$ desponta nos cuidados e na transmissão do conhecimento sobre a cosmovisão terapêutica em saúde. Seu sistema religioso de cura se diferencia da medicina oficial por explicar a doença mediante um contexto sociocultural mais abrangente, no qual se insere o doente (RABELO, 1994). "Ao invés das explicações reducionistas da medicina, os sistemas religiosos de cura oferecem uma explicação à doença que a insere no contexto sociocultural mais amplo do sofredor" (RABELO,1994,p.47). Como nos lembra Lévi-Strauss, em “O feiticeiro e sua magia”(1975),

Templo religioso dedicado às religiões de matrizes africanas como o Tambor de Mina, o Candomblé e em alguns momentos a Umbanda. Tem como sacerdote Pai Salvino de Jesus. Denomina-se por uma Associação Beneficente com a finalidade de organizar o segmento de religiosidade de Matrizes Africanas em Macapá/AP, tanto da parte jurídica, através da organização das Instituições, quanto de associações e outros. 
a eficácia da magia está na crença da magia.Trata-se, então, de pensar nesse consenso como o que aproxima comunidade e práticas mágico-religiosas, fundamentada em uma cosmologia que admite a existência de seres encantados com poder de afetar as condições humanas em suas várias dimensões da vida, sobretudo a de saúde. Nessa perspectiva, o terreiro aqui analisado se apresenta como um espaço de promoção de saúde, tendo em suas terapêuticas mecanismos naturais e sobrenaturais, dando ênfase ao acolhimento, às técnicas das rezas, à manipulação de poções e receituários de ervas e banhos, possibilitando uma visão ampliada e holística do processo saúde-doença.

Nesse contexto, o terreiro mostra uma missão social intensa, está inteiramente integrado à comunidade em seus valores, costumes e linguagem e, sendo assim, se revela importante 'mediador' da ação governamental nas estratégias de atenção à saúde para o alcance da melhoria das condições de vida e de saúde da população do seu entorno. Assim, considerando-se terreiro e Estratégia de Saúde da Família², como duas formas de atenção à saúde com dinâmicas especificas e particulares, o que acontece quando se juntam duas medicinas que seguem lógicas e concepções de mundo contrastantes? A 'comunicação' entre saúde e sagrado, no ambiente de um terreiro de candomblé, é o primeiro 'estranhamento' que move este estudo: o que permitiu esse arranjo, esse sincretismo entre a prática médica e a prática religiosa? Buscando responder essas indagações, proponho, aqui, uma análise das interfaces desses dois universos culturais - profissionais de saúde e o terreiro enquanto agência de saúde na comunidade pesquisada.

Exponho a narrativa desse percurso etnográfico enfocando os discursos (práticas de sentidos) produzidos nas relações e experiências sociais estabelecidas com meus interlocutores em territórios distintos, representados pela medicina popular e pela ciência médica. O artigo aborda o modo como esses dois sistemas de saúde operacionalizam suas práticas, e discute a viabilidade dessa interface enquanto agência governamental por esquemas culturais pré-existentes. São enfatizadas

2 A Estratégia Saúde da família (ESF) foi criada pelo Ministério da Saúde com o objetivo de consolidar o Sistema Único de Saúde (SUS) que tem como base os princípios de acesso, tais como a equidade, integralidade e universalidade e, também, princípios organizativos como a descentralização, participação da comunidade e regionalização (FRANCO, T.B; MERHY, EE, 2003). 
algumas características dos dois sistemas de saúde e a importância dessa junção para o cotidiano da população atendida por esses sistemas de cura. As descrições e narrativas apresentadas se baseiam em uma pesquisa de cunho etnográfico, com quatro anos de duração. O trabalho permitiu aproximações etnográficas com praticantes da medicina tradicional, profissionais da equipe ESF e usuários desses serviços no bairro pesquisado.

\section{Saúde no terreiro}

O dia amanhece e as portas do terreiro se abrem. O sacerdote Salvino sabe das muitas questões que lhe chegam cotidianamente, e se prepara para enfrentá-las consultando seus oráculos, se revestindo das orações, dos rituais litúrgicos, e depositando as obrigações diárias aos seus guias e orixás, sabendo que algumas ou muitas pessoas virão procurá-lo. Escutará pedido de ajuda para diversas situações. Também aconselhará aqueles que estão em busca de superar suas crises financeiras, de recuperar um amor perdido, de reaver um emprego, de alcançar o equilíbrio emocional ou mesmo sua condição de saúde. Muitos chegarão simplesmente pelo acolhimento espiritual, por uma desconfiança de má sorte, uma doença que não sara. Para reverter esses sofrimentos o sacerdote se reveste das rezas, milongas, mandingas, consulta oracular, prescrições, realização de rituais, jogo de búzios, atividades rotineiras em sua prática religiosa.

Os atendimentos no terreiro também se estendem a questões menos complexas - rezar sobre uma criança com ‘quebranto' ou de um adulto com a 'carne rasgada'. Este último procedimento resume-se a uma terapia de massagem, seguida da benzeção de 'costura'. A terapêutica se constitui de uma prática de reza seguida de um ritual em que o sacerdote coloca uma das mãos sobre o local enfermo e com a outra, dotada de agulha e linha, reproduz gestos como se estivesse costurando o local 'rasgado'. Presenciei a terapêutica em um homem de 43 anos, trabalhador de área de garimpo, e que devido ao esforço repetitivo 'sentiu sua carne da costa se rasgar'.

Uma de minhas interlocutoras, Lúcia, contou-me que suas idas ao terreiro de Pai Salvino iniciaram devido a 'palpitações' que sentia. 
Segundo ela, os remédios 'passados' pelo médico em nada resolveram e continuou a sentir as alterações. Imediatamente, resolveu procurar outro jeito para se tratar. Relatou-me que sempre foi uma mulher muito nervosa, alterando-se por 'qualquer coisa', e a melhora ocorreu quando iniciou o 'tratamento' no terreiro. O remédio indicado para suas palpitações foi a 'mistura' de folhas de maracujá, espinho branco e 'grelinhos' de jambú que não 'treme', fervidos em determinada quantidade de água. É um chá que deve ser tomado várias vezes ao dia até que a pessoa sinta que expeliu uma espécie de 'vento' que se localiza debaixo da palpitação. Embora Lúcia tenha sido advertida sobre o fato de ter uma doença perigosa, admite a diminuição das palpitações, mesmo quando se aborrece.

Outro caso foi o de Dona Iraci, de 64 anos, acometida de um 'derrame', e por se julgar muito nova para ter sido vitimada pela doença decidiu parar a fisioterapia recomendada por sua médica. Segundo Iraci, o tratamento seria muito 'chato', não se sentia feliz com aqueles exercícios repetitivos, e 'endireitar' sua boca 'torta' que a 'enfeava' - sequela de desvio de boca provocada pelo AVC - era seu principal objetivo. Ela soube, na clínica do tratamento, que a reversão das sequelas levaria algum tempo. Então, julgando que não havia melhorado nada com a fisioterapia, Iraci soube dos remédios preparados no terreiro para esse mal. E ela narrou-me o procedimento terapêutico e os 'ingredientes' nele utilizados:

O que mais me incomodava era a minha boca torta e mole, eu falava meio assim parece criança que tá falando. Aí isso eu não aceitava e meus filhos diziam pra eu ter calma, só que eu não tive. O resto tá tudo bem comigo. Aí quando eu cheguei lá, ela (mãe de santo) fez as friç̧ão e benzimento. E parecia que eu tava sentindo câimbra, câimbra e quando ela soltava aquilo ia desaparecendo e me aliviava da boca pro lado torta. Eu vim, vim e muito tempo depois já falava melhor a língua tava quase normal como antes. Ela usou em mim os remédios caseiro, melhor coisa mana, ela socava essas plantas daí do lado da casa dos cabocos dela, eu vi folha de pirarucu, a casca do breu branco, o resto não vi, e botava em cima massageando,rezando e com fé olha agora vê o resultado. E eu que ia ficar um tempão nessa fisioterapia? Eu não! Aqui foi um santo remédio. Eu sou católica, vou na igreja dos crentes e gosto, mas aqui foi um santo remédio (risos). (Entrevista realizada em fevereiro de 2014) 
Outro tratamento muito procurado no terreiro é para a 'esipla' (erisipela). A doença, às vezes, é associada à feitiçaria. $\mathrm{O}$ rezador Tito, filho de santo, disse-me que as pessoas chegam com a certeza de que a doença seria um feitiço, pela forma que se manifesta e as características apresentadas. Conhecida popularmente como febre de Santo Antônio, a 'esipla' é explicada por seu Tito como doença provocada pela falta de circulação do sangue. Se a pessoa fica muito parada, anda pouco, se acocora continuadamente e não deixa o sangue correr, produz uma espécie de inchaço duro que se estabelece, geralmente nas pernas. Nesse processo, a pessoa sente as pernas pesarem, incham e o lugar afetado vai ficando preto e depois deformado pela ferida ali produzida. Considerei interessante outra informação dada por seu Tito, a de que a manifestação da erisipela está associada à pessoa que tem 'chulé', 'frieira' ou 'cobreiro' no pé. Ele me explicou o procedimento que usa para tratar a moléstia e a reza que acompanha:

Ela é quente, então eu benzo com uma oração que eu tenho. Ai eu vou rezando e lavando a esipra e tirando as peles que solta com uma tesoura e gosto de usar gases brancas que é queimada e tu vai limpando e rezando e cortando e enxugando. Tem que ter a paciência, por isso quando trato eu marco o dia sempre de manhã, hora de a pessoa tomar banho vestir a roupa limpa, tomar um bom café pra ficar pronta pra o tratamento, de tarde eu não gosto, é muito quente. Eu também mando suspender todo o remoso. O peixe de pele nem pensar, tipo de caça que aqui se gosta muito de comer não pode, o camarão não também, nem pato e galinha também tem que evitar. Dependendo de como tá a ferida eu uso a goma da tapioca feita uma papa, a folha do pirarucu que rápido ingilha e seca, eu gosto do grude da tartaruga eu sempre encomendo pra isso. A reza é com fé, eu digo pra pessoa se ela tem fé vai ficar boa. Rapidinho ela fica boa (Entrevista realizada em março de 2014).

A reza, oração ou benzimento tem função terapêutica coadjuvante em todo o processo de tratamento elaborado por poções, chás de plantas, banhos, emulsões e misturas. São liturgias consideradas indispensáveis no procedimento de cura respaldadas pela fé, como anunciadas nas diversas falas aqui elencadas. A oração acompanha a fricção, massagem, a tesoura cortando, a agulha costurando. Os gestos são desenvolvidos tanto em adultos quanto em crianças. São repetitivos de outros proce- 
dimentos iguais àquele para retirar quebranto, o mau-olhado, espinhela caída e outras mazelas.

Esse universo religioso de saúde ocupa um lugar significativo na esfera da vida social da cidade amapaense, suas representações de cura, referentes às entidades espíritas, e atuam nas práticas da vida cotidiana de seus adeptos e não adeptos. O universo do terreiro, portanto, está no domínio das intervenções mágicas, nas diversas formas de interrogar e intervir nas trajetórias das pessoas que o procuram, de desvendar o oculto, de perceber e manipular o corpo, de alterar os sentimentos e as vontades; nele habitam os problemas essenciais dos indivíduos, as angústias perante as adversidades da vida, a relação de dependências humanas, o conhecimento do passado, do presente e do futuro. O terreiro não é um 'caminho' para Deus no sentido da cosmologia religiosa, mas uma forma de convivência com a purificação, o misticismo e a transcendência de seus santos, orixás e caboclos.

Na concepção clássica de Durkheim, a religião seria "uma coisa eminentemente social" (1996, p.9), o principio e o fim de uma relação com a vida, sua dimensão espiritual é povoada de mitos, recoberta de supertições, de emotividade, um caminho ou percurso para além do eu humano, de caráter simplista, teologal e místico, capaz de 'diluir', 'solucionar' e 'encaminhar' os dramas mais corriqueiros da vida humana, aliás, "foi a ciência e não a religião, que ensinou aos homens que as coisas são complexas e difíceis de compreender" (IDEM)

O saber adquirido de uma longa tradição, o propósito da escuta e do aconselhamento, a disponibilidade de tempo e a importância dada a cada caso que chega ao terreiro diminuem as distâncias sociais e morais, entre outras. Dentro do 'diagnóstico' religioso, a experiência pessoal em determinada situação, a exemplo da enfermidade, abre variadas possibilidades de interpretação, inclusive a de que alguns casos são mesmo para o terreiro.

São situações como as de Lúcia, Iraci e outros que movimentam os itinerários terapêuticos do Ylê da Oxum Apará, são adeptos e não adeptos. São pessoas movidas pelo poder da magia, acionadas pela eficácia da sabedoria, do 'dom' que possui o curador e o efeito do remédio por ele receitado (LÉVI-STRAUSS,1975), com o intuito de alcançar o alento para seus males. Assim, é importante entender como a força 
coercitiva dessa crença coletiva é capaz de construir e alterar verdades inteiramente assimiladas subjetivamente. Dessa forma, "a ação mágica e sua eficácia desvenda para o indivíduo "doente" uma dimensão espiritual da vida que é "trabalhada" pelo médium [...] organizada dentro de um discurso que "explica" a doença" (MONTERO,1985, p.131).

O Ylê do Oxum Apará apresentam-se, nesse contexto, como importante espaço na promoção da saúde; na promoção de práticas terapêuticas alternativas, baseadas na tradição religiosa, em que a ancestralidade do corpo está relacionada à sua capacidade de centralizar forças que devem ser unidas em uma relação de equilíbrio. O equilíbrio das diversas partes do corpo, do mundo natural e sobrenatural constitui o indivíduo. Na amplitude deste estudo, o corpo é entendido como expressão e materialização de uma condição social e um habitus expressado na forma de posturas corporais e investimentos na sua produção (BOURDIEU, 1989). Assim, é através da vivência e da iniciação em terreiro que se internaliza uma visão de mundo específica, que privilegia o corpo humano e a saúde.

Pai Salvino, como agente de cura, tem uma visão particular da concepção de doença. Em sua concepção religiosa, a doença é entendida como a desordem do corpo, e para o alcance da cura deve haver um processo de reequilíbrio e então compor a ordem, sendo o corpo parte integrante desse processo. Contudo, tal estado não se restringe a problemas de saúde. A noção de desequilíbrio, do desajuste das emoções, como o nervoso sentido por Lúcia, é incorporada também como situação de 'desordem'. A noção de saúde na visão das religiões afro-brasileiras extrapola o simples bem-estar físico, apresentando-se como "campo ordenador que confere ao indivíduo iniciado uma diretriz de comportamento" (GOMBERG, 2011, p.144).

No processo de cura religioso há de se seguir uma série de prescrições e de ritos definidos a partir da consulta oracular, geralmente o jogo de búzios, feito pelo pai de santo da casa, a realização do ebó ${ }^{3}$, considerado um recurso terapêutico fundamental para o restabelecimento da saúde do indivíduo. Essas funções terapêuticas visam à restituição do

3 O ebó é uma oferenda a ser feita para os ancestrais ou orixá em agradecimento à benção recebida ou na intenção de resolver problemas ou obstáculos, abrir portas e oportunidades. É usado para denominar um processo de limpeza, chamado também de sacudimento, por muitos. 
equilíbrio ao indivíduo. Os diagnósticos, as prescrições e os tratamentos integram uma cosmologia de concepções mágico-religiosas, dentro de um conjunto de relações sociais e de princípios básicos desse universo que as legitimam, devendo, por isso, ser compreendidos em sua complexidade social (LAPLATINE,1989). Nesse contexto, "a magia é, por definição, objeto de crença" (MAUSS,1974, p.122).

Minha vivência no Ylê da Oxum Apará me possibilitou perceber o quanto é dinâmica a produção de seus saberes e tradições que, através de sua visão de mundo, compreendem formas diferenciadas de lidar com a saúde, a doença e outras adversidades que lá chegam. É um espaço terapêutico organizado em harmonia com a maneira popular de perceber as adversidades, a exemplo da doença e seus diferentes modos de expressão. Para o caso da doença, ela "perde, portanto, no contexto religioso, seu conteúdo orgânico original e se torna um acontecimento simbolicamente significativo que organiza e pontua a biografia individual" (MONTERO,1985, p.98). É rico seu espaço, culturalmente constituído, em que pessoas moldam concepções, práticas e crenças a respeito das diversas formas de adoecer, sarar e enfrentar as desventuras.

\section{A ESF em termos cosmológicos}

Para compreender a proximidade entre a ESF e o terreiro Ylê da Oxum Apará faz-se necessário conhecer o campo de atuação dessa política de saúde e como a população adstrita interage com o programa no enfrentamento da doença e seus recursos de cura. A ESF, uma das manifestações do Sistema Único de Saúde - SUS, se apresenta como uma política de organização da rede de serviços em saúde que traz como proposta a reorientação do novo padrão assistencial, demandado da compreensão de que a saúde sempre esteve tradicionalmente caracterizada por noções universalistas sobre aspectos que envolvem a saúde e a doença. Interpretadas por parâmetros biomédicos, a doença e a cura se constituem em uma base horizontal para a qual as questões subjetivas, culturais e sociais pouco influem na definição do diagnóstico médico e seus receituários. Assim, a saúde coletiva surge em oposição à saúde pública tradicional, instituída de um modelo curativo e hospitalocêntrico, realidade distanciada das camadas populares mais pobres. 
A ESF ocupa, atualmente, importante função nas políticas de saúde no Brasil, tendo como desafio fortalecer o mérito da atenção primária e, simultaneamente, a da saúde comunitária. Por meio dessa proposta, o trabalho da equipe - composta de médicos (as), agentes de saúde comunitários, enfermeiros, dentistas e técnicos de enfermagem constitui-se em elo essencial entre a instituição saúde e a comunidade. A estratégia de estabelecer vínculos com a população atendida, e a de integrar em suas ações de cura e prevenção a conjugação dos conhecimentos biológicos, sociais e culturais na concepção saúde/doença, é a base que permitiu ao programa viabilizar o mérito da atenção primária e da saúde comunitária.

A prática de trabalho estabelecida pela ESF se vale das concepções antropológicas sobre a integração entre políticas de saúde e práticas de medicina popular, iniciada oficialmente com a Declaração de Alma $\mathrm{Ata}^{4}$, por ocasião da Conferência Internacional sobre Cuidados Primários de Saúde, no Cazaquistão, em 1978. Nessa Declaração, a Organização Mundial da Saúde (OMS) acenou aos países membros que buscassem a cooperação da população, desfrutando de seus conhecimentos sobre medicina tradicional, avaliando suas necessidades e peculiaridades locais, sociais e culturais.

O modelo de saúde pensado em Alma-Ata estimulou outras organizações internacionais a desenvolver acordos de valorização do sistema tradicional de cura. Entre estas organizações estão a Organização das Nações Unidas para a Educação, a Ciência e a Cultura (UNESCO) e a Organização Pan-americana da Saúde sobre Medicina Tradicional e Terapias Alternativas(2002), que admitiram a importância dos aspectos culturais no planejamento de políticas públicas em saúde, considerando que "as doenças, a saúde e a morte não se reduzem a uma evidência orgânica, natural e objetiva, [...] está intimamente relacionada com características organizacionais e culturais de cada sociedade" (MINAYO,2006, p.205).

4 Conferência Internacional sobre Cuidados Primários de Saúde ocorridos no ano de 1978 no Cazaquistão. Declaração da Alma-Ata da Organização Mundial da Saúde (OMS) expressou a necessidade de ação urgente de todos os governos, de todos os que trabalham nos campos da saúde e do desenvolvimento e da comunidade mundial para promover a saúde de todos os povos do mundo. 
Para o alcance de suas metas, o programa ESF, norteado pela concepção de integralidade ${ }^{5}$, se desdobra no atendimento à comunidade do entorno do terreiro nas situações de complexidade de doenças e seus controles. Preventivamente, conforme já mencionado, atua no controle da mortalidade materna e infantil, saúde do idoso, grupos de risco DST e AIDS, cuidados do diabetes, da hipertensão, e de outras síndromes de significativa incidência nessa população carente.

Portanto, a incorporação do terreiro na ESF é um aporte para uma reestruturação das práticas de cura para além dos muros institucionais dos serviços de saúde. O sincretismo entre esses dois sistemas de cura possibilitou não somente uma visão mais holística do processo saúde/ doença, mas dos valores, dos modos de vida, das relações afetivas e simbólicas da comunidade, sabendo que a cultura interfere diretamente nas representações que os indivíduos fazem sobre modos de adoecer e sarar. Se a proposta da ESF é a de estabelecer vínculos entre profissionais de saúde, o paciente e seu meio social, é extremamente 'saudável' que essa política de saúde, ao dialogar com a população, se articule e até se represente em seus costumes e tradições, indicando que "a esfera pública aparece assim como uma forma prática da esfera cosmológica" (SAHLINS, 1988, p.82).

Mudanças de paradigmas e ações públicas em saúde, historicamente, levam a população a adotar posições e desconfianças em relação às instituições promotoras e seus técnicos, mas ao mesmo tempo agenciam e deixam em aberto às negociações e proximidades. Em diferentes e iguais estratégias, terreiro e política de saúde articulam, embora em diferentes cosmologias, modos de sarar e cuidar. Assim, tal encontro proporcionou a elaboração de uma espécie de 'termo de cooperação técnica' entre o sagrado e a ciência, sendo ratificado pelos moradores do bairro, cujo teor é o uso 'racional' das terapêuticas nos diferentes recursos em saúde.

Um dos princípios do Sistema Único de Saúde. Busca garantir ao indivíduo uma assistência à saúde que transcenda a prática curativa, contemplando o indivíduo em todos os níveis de atenção e considerando o sujeito inserido em um contexto social, familiar e cultural (MATTOS,2004). 


\section{Considerações finais}

Interessou neste estudo, analisar as conexões políticas, sociais e culturais entre duas agências de saúde com roteiros terapêuticos diferentes, que traduzem lógicas, trajetórias e biografias aparentemente distintas. A relação política entre saúde e sagrado surgiu da intenção aberta de aproveitar o status que possui o terreiro no bairro. Ao redor do terreiro há escolas, supermercados, consultórios médicos, galpões de lojas e residências de elevado padrão arquitetônico, a maioria ocupada por funcionários públicos e empresários. Também nesse entorno reside a população que ocupa as vielas — ruas sinuosas e íngremes algumas sem placa de sinalização e numeração confusa, dificultando, pelo seu estreitamento, a passagem de veículos. Essa população vive em casas pequenas, estruturadas de forma mais simples, e muitas acomodam grandes famílias.

O sacerdote Salvino desenvolve um trabalho social, de atendimento às famílias, distribuindo, mensalmente, cestas básicas à comunidade do entorno do terreiro ${ }^{6}$. Sua Associação desenvolve o projeto em parceria com a Secretaria de Assistência Social do município local. No último domingo de cada mês, pela manhã, o terreiro organiza a distribuição dos alimentos a determinadas famílias, a maioria representada por mulheres e idosos, pois estes são os principais critérios para integrar o projeto. Essa interação social com a comunidade fez do pai de santo seu representante nas situações de reivindicação junto aos órgãos públicos e, sendo assim, ele se apresenta como um 'tradutor' — no sentido da linguagem — da forma como as pessoas se expressam ou dizem o que querem para reivindicar suas necessidades. A ideia de 'tradução' está presente em Geertz (2001), considerada uma forma de discernir determinadas linguagens para, a partir delas, construir as dinâmicas que potencializam o cotidiano e haja entendimento e diálogo.

No processo de acompanhamento do projeto desenvolvido entre ESF e terreiro, percebi que terreiro e comunidade estabeleceram uma

6 A categoria comunidade vem sendo alvo de questionamentos e perdeu espaço nas análises sociológicas. Todavia, partilho a convicção de que essa categoria analítica tem significativo vigor explicativo para o estudo das formas de sociabilidade gestadas no âmbito dos grupos amazônicos. Tomo-a no mesmo sentido utilizado por Dulcet (1999,p.47), ao conceituá-la como "grupo humano com sentido de coparticipação de relações ou sentimentos". 
linguagem própria. E essa capacidade de chegar à população por meio da compreensão de sua linguagem, do seu 'jeito de ser', faz com que a Associação do Ylê do Oxum Apará acabe por representar também os interesses do poder público na relação com a comunidade. Essa área de atuação da política de saúde agrega questões sociais graves, por exemplo, a do crime por tráfico de drogas, assaltos, gangues, entre outras violências. Isso significa maior alcance de contatos e aproximações do terreiro com a população pelas questões apresentadas, o que lhe proporciona maior abrangência se comparada às instituições do Estado.

Os detalhes aqui etnografados, de reconhecimento do local, é para dizer que ter um representante religioso nesse tipo de espaço significa possuir certo 'controle', inclusive para a entrada de aparelhos institucionais, como no caso da ESF que se deslocou de sua UBS para dentro do espaço religioso, no intuito de alcançar a população doente. A partir dessas explicações, em favor dessa realidade, a ciência médica, como ponto oficial em sua estratégia, intenta aproveitar as experiências e os conhecimentos da medicina tradicional praticados no terreiro. Assim, considera ser esse um fio condutor para atender ao modelo biopsicossocial preconizado na Política de Humanização do SUS, em um sistema que pondere as necessidades, os recursos locais e as características sociais e culturais de sua população.

$\mathrm{O}$ elo entre instituição e tradição trouxe a expectativa de novos conhecimentos. Na produção em saúde, onde precisamente estou, o contato entre os dois sistemas - o oficial e o tradicional -, não ocorreu sem estranhamentos. O domínio das técnicas, as distintas interpretações da doença e as visões de mundo acerca da relação homem-natureza foram os principais 'tensionamentos' vividos na junção desses dois conhecimentos de cura, e embora sejam saberes socialmente legitimados não deixam de estar em oposição um ao outro. Sendo assim, como já mencionado, se estabelecem no campo social de poder e tensões, exercido e estabelecido por posições sociais arbitrárias, equivalente ao que pode ser obtido pela força física ou econômica (BOURDIEU,2003).

Convivendo no 'estranhamento' entre a ciência e a crença, onde poderia haver um ponto convergente entre esses saberes? Seguindo suas 'trilhas', vislumbrei um encontro na encruzilhada da cura e, como pude observar - em algumas ocasiões de atendimento da ESF, na rotina do 
terreiro -, que a complementaridade entre ciência e crença ocorre pela 'fé'. Na 'fé' de quem busca a cura pelo remédio receitado pelo médico ou pelo unguento benzido pelo rezador. Surge aí, um arranjo entre o visível e o simbólico capaz de se efetivar na cura.

Quando o terreiro aceitou compartilhar com os profissionais de saúde da ESF o 'espaço da cura', de certa forma ambos fizeram 'concessões' que contrariam suas 'literaturas', pois refletem ciências distintas, e, portanto, precisaram aprender a flexibilizar não somente suas posições de saberes, mas também suas cosmovisões institucionais. Resulta desse arranjo social uma relação de poder presente no cotidiano do terreiro e dos profissionais de saúde que têm, como contrapartida, a ocupação, pela população, do espaço de saúde, em busca de atendimento social e da acolhida religiosa.

Em síntese, o terreiro não é apenas um lugar de atendimento especializado em saúde ou espaço de exercício da caridade. É certo que ele comporta outras dimensões da vida social, possibilitando análises sob outras perspectivas. É fato que, enquanto saber oficial, a instituição saúde, se impõe em determinados momentos, criando situações e estabelecendo espaços de ações de acordo com suas possibilidades e visão de mundo. Por outro lado, também é fato que o terreiro tem se apropriado da parceria com o programa e exercido um tipo singular de poder junto aos seus adeptos e não adeptos, o que lhe garante prestigio diante de sua comunidade religiosa e seu entorno populacional, ratificando sua posição política/carismática no ambiente da gestão política municipal da cidade de Macapá. E mais: o status do terreiro, ao ser considerado um 'parceiro da saúde', serve como 'barganha' política a gestores públicos que se dizem o idealizador da ação, cabendo questionar se o mesmo não está sendo aliado da cultura hegemônica que reforça a prática biomédica, pois o Sacerdote da casa de santo é o responsável 'legal' pela mediação entre comunidade e o atendimento ESF.

\section{Referências}

ACHTERBERGER, J. A imaginação na cura: xamanismo e medicina moderna. São Paulo: Summus, 1996. 
BOURDIEU, P. O Poder Simbólico. Rio de Janeiro: Bertrand,2003.

BRASIL.Ministério da Saúde. Experiências Inovadoras no SUS: relatos de experiências. Brasília,2002.

DULCET, S. R. A Produção Simbólica da Festa do Çairé: drama, cultura e representação em Alter-do-Chão, Santarém - PA. Dissertação de Mestrado. Belém: NAEA,1999.

DURKHEIM, E. As Formas Elementares da Vida Religiosa. São Paulo: Martins Fontes, 1996.

FRANCO, T.B; MERHY, EE. Programa Saúde da Família (PSF): Contradições de um programa destinado à mudança do modelo tecnoassistencial. In: Merhy EE, organizador. O trabalho em saúde: olhando e experenciando o SUS no cotidiano. São Paulo: Editora Hucitec; 2003.

GEERTZ, C. A Interpretação das Culturas. Rio de Janeiro, Zahar,1989.

GOMBERG, E. Hospital de Orixás: encontros terapêuticos em um terreiro de candomblé. Salvador: EDUFBA,2011.

HELMAN, C. G. Cultura, saúde e doença. Tradução: Cláudia Buchweitz e Pedro M. Garcez. $4^{\mathrm{a}}$ edição. Porto Alegre: Artemed,2003.

LAPlatine, F. Antropologia da doença. São Paulo: Martins Fontes,1989.

LOYOLA, M. A. Médicos e Curandeiros: conflito social e saúde. São Paulo: DIFEL, 1984.

LÉVI-STRAUSS, C. O Feiticeiro e sua Magia. In: Antropologia Estrutural. Rio de Janeiro: Tempo Brasileiro,1975.

LÉVI-STRAUSS, C. A Eficácia Simbólica. In: LÉVI-STRAUSS,Claude. Antropologia estrutural. 5.ed. Rio de Janeiro: Tempo Brasileiro,1996.

LIMA, V.da C. A Família de Santo nos Candomblés Jejes-Nagôs da Bahia: um Estudo de Relações Intragrupais. Salvador: Corrupio,2003.

LOUREIRO, J.de J. P.. Cultura Amazônica: uma poética do imaginário. Belém: CEJUP, 1995.

LOYOLA, M. A.. Médicos e Curandeiros: conflito social e saúde. São Paulo: DIFEL, 1984 .

MAUÉS, R. H. Medicinas populares e pajelança cabocla na Amazônia. In: ALVES, P. C. e MINAYO, M. C. S (Org.). Saúde e Doença: um olhar antropológico. Rio de Janeiro: FIOCRUZ,1994.

MAUSS, M. Sociologia e Antropologia. São Paulo: EPU/EDUSP,1974.

MATTOS, R. A. A integralidade na prática (ou sobre a prática da integralidade). Caderno Saúde Pública, vol.20 n5, Rio de Janeiro, set/out,2004. 
MINAYO, M. C. S. Contribuições da antropologia para pensar e fazer saúde. In: CAMPOS, G.W.S. et al. (Org.). Tratado de saúde coletiva. São Paulo: Hucitec; Rio de Janeiro: Fiocruz,2006.

MONTERO, P. Da doença à desordem: a magia na umbanda. Rio de Janeiro: Edições Graal, 1985.

Organización Mundial de la Salud. Estrategia de la OMS sobre medicina tradicional 2002-2005. Genebra; 2002.

RABELO, M.C. M. Religião e cura: algumas reflexões sobre a experiência religiosa das classes populares urbanas. Cadernos de Saúde Pública, $n^{\circ}$ 9, p.316-325,1993.

RABELO, M.C. M. Religião, Ritual e Cura. In: P. C. A; M. C.S. M.(Org.) Saúde e doença: um olhar antropológico. Rio de Janeiro: Editora FIOCRUZ,1994.

RODRIGUES, J. C. Tabu do corpo. Rio de Janeiro: Editora Fiocruz;2006.

ROUÉ, M. Novas Perspectivas em Etnoecologia: "Saberes Tradicionais" e Gestão dos Recursos Naturais. In CASTRO, Edna \& PINTON, Florence at al (Orgs.) Faces do Trópico Úmido: conceitos e novas questões sobre desenvolvimento e meio ambiente. Belém: CEJUPUFPA-NAEA, 1997.

SAHLINS, M. Ilhas de história. Rio de Janeiro: Zahar,1999. 1997. “O 'pessimismo sentimental e a experiência etnográfica: porque a cultura não é um 'objeto` em vias de extinção (parte II)". Mana 3.

. 1988. Cosmologias do capitalismo: o setor trans-pacífico do "sistema mundial”. In: Anais da XVI Reunião Brasileira de Antropologia. Campinas. 